EDITOR'S

CHOICE

\title{
Ambient air pollution and risk of congenital anomalies in England, 1991-1999
}

\author{
H Dolk, ${ }^{1}$ B Armstrong, ${ }^{2} \mathrm{~K}$ Lachowycz, ${ }^{2} \mathrm{M}$ Vrijheid, ${ }^{2,3} \mathrm{~J}$ Rankin, ${ }^{4}$ L Abramsky, ${ }^{5}$ \\ P A Boyd, ${ }^{6}$ D Wellesley ${ }^{7}$
}

\section{See Editorial, p221}

- An additional appendix is available online only at http:// oem.bmj.com/content/vol67/ issue 4

${ }^{1}$ Public Health and Primary Care Research Group, Institute of Nursing Research, University of Ulster, Newtownabbey, UK ${ }^{2}$ Department of Public Health and Policy, London School of Hygiene and Tropical Medicine, London UK

${ }^{3}$ Centre for Research in Environmental Epidemiology (CREAL), Municipal Institute of Medical Research, Barcelona,

Spain

${ }^{4}$ Institute of Health and Society, Newcastle University, Newcastle upon Tyne, UK ${ }^{5}$ North Thames (West)

Congenital Anomalies Register, Harrow, UK

${ }^{6}$ National Perinatal Epidemiology Unit, Oxford, UK

${ }^{7}$ Wessex Clinical Genetics

Service, Southampton, UK

\section{Correspondence to}

Professor Helen Dolk, Room 12L09, University of Ulster, Shore Road, Newtownabbey, Co. Antrim, BT37 00B, UK; h.dolk@ulster.ac.uk

Accepted 6 August 2009

Published Online First

9 October 2009

\section{ABSTRACT}

Objectives To investigate whether there is an association between risk of congenital anomaly and annual ward level exposure to air pollution in England during the 1990s.

Methods A geographical study was conducted across four regions of England using population-based congenital anomaly registers, 1991-1999. Exposure was measured as 1996 annual mean background sulphur dioxide $\left(\mathrm{SO}_{2}\right)$, nitrogen dioxide $\left(\mathrm{NO}_{2}\right)$ and particulate matter $\left(\mathrm{PM}_{10}\right)$ concentrations at census ward level $(n=1474)$. Poisson regression, controlling for maternal age, area socioeconomic deprivation and hospital catchment area, was used to estimate relative risk for an increase in pollution from the 10th to the 90th centile.

Results For non-chromosomal anomalies combined, relative risks were $0.99(95 \% \mathrm{Cl} 0.93$ to 1.05$)$ for $\mathrm{SO}_{2}$, 0.97 (95\% Cl 0.84 to 1.11) for $\mathrm{NO}_{2}$ and 0.89 (95\% Cl 0.75 to 1.07) for $\mathrm{PM}_{10}$. For chromosomal anomalies, relative risks were 1.06 (95\% Cl 0.98 to 1.15) for $\mathrm{SO}_{2}, 1.11$ (95\% $\mathrm{Cl} 0.95$ to 1.30$)$ for $\mathrm{NO}_{2}$ and $1.18(95 \% \mathrm{Cl} 0.97$ to 1.42$)$ for $\mathrm{PM}_{10}$. Raised risks were found for tetralogy of Fallot and $\mathrm{SO}_{2}(\mathrm{RR}=1.38,95 \% \mathrm{Cl} 1.07$ to 1.79$), \mathrm{NO}_{2}(\mathrm{RR}=1.44$, $95 \% \mathrm{Cl} 0.71$ to 2.93 ) and $\mathrm{PM}_{10}(\mathrm{RR}=1.48,95 \% \mathrm{Cl} 0.57$ to 3.84), which is of interest in light of previously reported associations between this cardiac anomaly and other air pollutants.

Conclusions While air pollution in the 1990s did not lead to sustained geographical differences in the overall congenital anomaly rate in England, further research regarding specific anomalies is indicated.

\section{INTRODUCTION}

There is growing epidemiological evidence for adverse effects on the fetus and newborn of maternal exposure to air pollution. ${ }^{12}$ The strongest evidence of a causal association relates to infant mortality, particularly postneonatal respiratory mortality, and low birth weight. ${ }^{1}{ }^{2}$ There is less evidence differentiating the two main components of low birth weight: preterm birth and intrauterine growth retardation. ${ }^{1}$ Two recent American studies of cardiac defects and oral clefts have suggested associations between specific pollutants and specific cardiac defects, ${ }^{3}$ and have been followed by further studies mainly concentrating on the same malformations. ${ }^{5-7}$ Possible mechanisms of teratogenicity are at this stage speculative ${ }^{1}$ but may include somatic effects on DNA interfering with basic processes such as programmed apoptosis (cell death), effects through early fetal growth, and indirect effects through maternal immune effects, infection, or asthma or related medication. DNA

\section{What this paper adds}

- Some studies have found an association between risk of specific congenital cardiac defects and maternal exposure to air pollution during pregnancy.

- Whether air pollution confers a risk for other types of congenital anomaly is largely unknown.

- This study finds no association between average annual exposure to $\mathrm{SO}_{2}, \mathrm{NO}_{2}$ and $\mathrm{PM}_{10}$ of the area of residence and risk of congenital anomalies in general or a wide range of specific congenital anomaly types.

- An association between risk of tetralogy of Fallot and exposure to $\mathrm{SO}_{2}$ was found.

adduct levels have been found to be higher in maternal blood and placentas in areas with high pollution levels. ${ }^{1}$ Maternal smoking is an analogous although stronger source of exposure to air pollutants for which there is some evidence of teratogenicity, particularly in relation to orofacial clefts, limb reduction defects and gastroschisis, ${ }^{8-11}$ but as yet there is no evidence for an effect of environmental tobacco smoke.

We report the results of a study analysing a population-based database of congenital anomalies in four regions of England for 1991-1999 to investigate associations between a wide range of selected congenital anomalies and mean annual ward level exposure to sulphur dioxide $\left(\mathrm{SO}_{2}\right)$, nitrogen dioxide $\left(\mathrm{NO}_{2}\right)$ and particulate matter $\left(\mathrm{PM}_{10}\right)$.

\section{METHODS}

\section{Design}

This was a geographical study examining the relationship between the congenital anomaly rate in census wards for 1991-1999 and relative annual average exposure to a range of air pollutants.

\section{Population and data}

We drew on data from a database that has been previously described. ${ }^{12-14}$ Data were contributed by four English registers of congenital anomaly (Wessex, North West Thames, Oxford, Northern) for the period 1991-1999 (1994-1999 for Wessex). These registers cover the cities of Southampton, part of London, Oxford and Newcastle, as well as surrounding areas, and all operate active ascertainment procedures. ${ }^{15}$ The study population comprised 759993 births (live and still) in 1474 census wards, after excluding 377 wards near boundaries where more than $20 \%$ of mothers were delivering in 
hospitals outside the area (where full case ascertainment was less certain). In the study area, $94.6 \%$ of mothers delivered in hospitals within the register areas. Cases were geographically located (by postcode of residence at delivery) down to census enumeration district, small areas comprising about 1000 residents. In three of the regions, a small proportion of cases could not be geographically located (North Thames 0.8\%, Wessex $6.3 \%$, Oxford $1.7 \%$ ). Births in each enumeration district, stratified by maternal age, were obtained from the Office for National Statistics and adjusted down pro-rata in enumeration districts in electoral wards in which less than $100 \%$ (ie, $80 \%-99 \%$ ) of births were in hospitals covered by the registry, and by the proportion of unlocated cases in each region. Maternal age was classified into the categories $<20,20-34,35+$ for non-chromosomal and $<30$, $30-34,35+$ for chromosomal anomalies (large pre-specified categories were required due to confidentiality restrictions over release of denominator data, and thus the most relevant categories were obtained for each group). The Carstairs index of deprivation ${ }^{16}$ was calculated for enumeration districts based on 1991 census data on social class of head of household, car ownership, unemployment and overcrowding, standardised to Great Britain. Study population enumeration districts were divided into quintiles according to their Carstairs score. Maternal age and socioeconomic deprivation were the only two relevant risk factors which could be obtained for both congenital anomaly cases (register data) and all births.

\section{Case definition and ascertainment}

We included cases of selected congenital anomalies among live births, fetal deaths from 20 weeks gestation, and terminations of pregnancy following prenatal diagnosis of any gestational age. ${ }^{12} 13$ Malformations were coded according to the International Classification of Diseases (ICD) version 9 or 10 (up to nine codes per baby/fetus). We included only anomaly types that are well defined and recorded by the agreement of participating registries. We excluded minor anomalies according to the standard European Surveillance of Congenital Anomalies (EUROCAT) exclusion list, ${ }^{17}$ anomalies which are often variably recorded (eg, ventricular septal defects (VSD)) or only recorded by one register (hypospadias), and tumours and neoplasms, metabolic anomalies and deformations. Mendelian syndromes were excluded. The range of ICD-10 codes for inclusion was as follows: Q00-03, Q041, Q042, Q05, Q110-112, Q160, Q172, Q20, Q211-219, Q22-23, Q25-26, Q300-348, O35-37, O390-394, Q41, Q42, Q600-605, Q61, Q641-43, Q645, Q794, Q71-73, Q77, Q78, Q790-793, Q90-94 and 096-99.

We classified cases into non-chromosomal and chromosomal anomalies. A priori decisions were made to analyse in addition the more frequent subgroups, based on EUROCAT coding subgroups for ICD-9 and ICD-10 (14): neural tube defects, hydrocephaly, cardiac defects, cleft lip with or without cleft palate, cleft palate, digestive system atresias, bilateral renal agenesis, cystic kidney disease, limb reduction, diaphragmatic hernia, omphalocele, gastroschisis, multiple anomalies and Down syndrome. In addition, the cardiac anomalies were split into the following subgroups, based on EUROCAT coding subgroups, ${ }^{17}$ due to the a priori interest in cardiac anomalies from previous studies: anomalies of cardiac chambers (Q20), transposition of great vessels (Q203), malformations of cardiac septa (excluding VSD) (Q21 excluding Q210), atrial septal defects (Q211, if verified after 1 month of age by echocardiography, postmortem, surgery or catherisation), atrioventricular septal defects (Q212), tetralogy of Fallot (Q213), malformations of valves (Q22-23), hypoplastic left heart (Q234), malformations of great arteries and veins ( $\mathrm{Q} 25-26$ excluding premature patent ductus arteriosus), coarctation of aorta (Q251) and patent ductus arteriosus (Q250, gestational age $\geq 37$ weeks).

Cases could belong to more than one non-chromosomal subgroup if they had multiple congenital anomalies. In addition, the subgroup 'multiple anomalies' comprised non-chromosomal cases with more than one major anomaly not belonging to a sequence or diagnosed syndrome $e^{18}$ as reviewed by two authors $(\mathrm{PB}, \mathrm{DW})$.

\section{Measurement of air pollution}

Maps of estimated annual mean background $\mathrm{SO}_{2}, \mathrm{NO}_{2}$ and $\mathrm{PM}_{10}$ concentrations at a $1 \mathrm{~km} \times 1 \mathrm{~km}$ grid resolution were obtained from the National Environmental Technology Centre for 1996, derived according to national methodology. ${ }^{19} 20$ Maps of carbon monoxide, ozone and other pollutants of interest were not available, nor were maps available for other years except 2001. Broadly, the estimates were based on a model in which each kilometre grid square concentration comprised two parts: a regional background and a contribution from local emissions. The regional background concentrations were derived from data from monitors far from local sources, and the local contribution from low-level emissions in the grid square and the 24 surrounding grid squares. Emissions were obtained from the UK National Atmospheric Emissions Inventory, which includes roads as well as stationary sources. The model parameters were estimated using monitoring data. Correlations of modelled and a sample of annual mean measured concentrations at monitoring sites not included in the original model in 1996 were 0.83 and 0.73 for $\mathrm{NO}_{2}$ and $\mathrm{SO}_{2}$, respectively. ${ }^{19}$ There were insufficient validation data to estimate such a correlation for $\mathrm{PM}_{10}$ for 1996 estimates, but a value of $\mathrm{r}=0.79$ was given for 2001 estimates, which were obtained using a similar approach. ${ }^{20}$

These maps were plotted using a geographic information system (GIS). Census ward level pollution concentrations were derived as population-weighted averages of pollution concentrations of the smallest census output areas, output area centroids having been mapped to $1 \mathrm{~km}$ squares by spatial overlay. This improved ward averaging of pollution measures in urban areas, where a high proportion of kilometre grid squares crossed ward boundaries. A check was made for stability of geographical pattern by comparing 2001 data with 1996; this revealed high correlations for output areas for $\mathrm{PM}_{10}$ and $\mathrm{NO}_{2}$ (both with correlations of 0.98$)$, but lower correlation for $\mathrm{SO}_{2}(r=0.54)$ for which average levels had also been declining markedly.

Correlations were examined between pollutants. $\mathrm{PM}_{10}$ and $\mathrm{NO}_{2}$ were highly correlated (0.93) but neither was highly correlated with $\mathrm{SO}_{2}$ (0.54 and 0.60 , respectively).

Levels of the three air pollutants in 1996 in the study area are shown in table 1

\section{Statistical analysis}

To simplify interpretation, cases with missing maternal age $(1.3 \%)$ and enumeration districts with deprivation index classified as unknown (0.4\%) were excluded from all analyses. Further, $0.7 \%$

Table 1 Tenth, median and 90th centiles of each pollutant (ward annual average, 1996)

\begin{tabular}{lcclc}
\hline Pollutant & p10 & p50 & p90 & $\begin{array}{l}\text { p10-p90 } \\
\text { range }\end{array}$ \\
\hline $\mathrm{SO}_{2}\left(\mu \mathrm{g} / \mathrm{m}^{3}\right)$ & 3.87 & 7.86 & 14.99 & 11.12 \\
$\mathrm{NO}_{2}\left(\mu \mathrm{g} / \mathrm{m}^{3}\right)$ & 21.48 & 35.11 & 47.78 & 26.30 \\
$\mathrm{PM}_{10}\left(\mu \mathrm{g} / \mathrm{m}^{3}\right)$ & 18.84 & 21.97 & 26.40 & 7.56 \\
\hline
\end{tabular}

p10, tenth centile; p50, 50th (median) centile; p90, 90th centile. 
of cases were dropped from analyses because no births were reported in the enumeration district in the same age group.

Because proportions of births resulting in anomaly were small, their sampling variation could be well approximated by a Poisson distribution, with the logarithm of number of births offset. We thus used a Poisson regression model of maternal agespecific enumeration district counts to adjust for maternal age, registry and area deprivation.

Earlier analysis ${ }^{13}{ }^{14}$ has shown that hospital catchment was also a determinant of anomaly rate, reflecting hospital diagnostic and recording practice. We adjusted for hospital catchment with two methods: (1) by including a fixed hospital catchment effect (ie, stratifying by hospital catchment) and (2) by including a random hospital catchment effect. ${ }^{21}$

The fixed effects model (which also allowed for random effects at ward level) provides the most robust control for confounding but involves substantial precision loss for pollutants for which most variation was between catchment areas. The hospital random effects model sacrifices some degree of control for confounding in order to gain some precision. It also ensures that confidence intervals are not spuriously small. The results in the tables include hospital catchment as a random effect. Tables including results using the fixed effect model are included in the online appendix.

The association of each pollutant (singly) with anomaly rate was estimated by including in the Poisson regression model the estimated concentration of pollution as a continuous variable (ie, all data were used in the models, not just the extreme centiles). The regression coefficients were scaled and exponentiated to represent anomaly risk for exposure at the 90th centile of pollution relative to exposure at the 10th centile (ie, a relative risk comparing the 90th exposure centile to the 10th exposure centile). Only one pollutant was considered in each model, due to the high correlation between pollutants.

\section{RESULTS}

For non-chromosomal anomalies overall, we found no evidence of an association with any of the pollution measures (table 2), and confidence intervals indicated that excess risks of an order of more than $10 \%$ were unlikely. For chromosomal anomalies (table 2) and Down syndrome specifically (table 3), there were non-significant excess risks in the order of $6 \%-18 \%$ for $\mathrm{SO}_{2}, \mathrm{NO}_{2}$ and $\mathrm{PM}_{10}$, with upper confidence limit bounds to $42 \%$ for $\mathrm{PM}_{10}$.

For the specific non-chromosomal subtypes (table 3), 42 associations were studied, with some raised risks found, generally with wide confidence intervals which included no excess risk. The association statistically least likely to be due to chance was a positive association between omphalocele and $\mathrm{PM}_{10}$ (unadjusted $R R=1.53$, fully adjusted $R R=2.17,95 \%$ CI 1.00 to 4.71 ). Omphalocele also showed a raised risk for $\mathrm{NO}_{2}$ (fully adjusted $\mathrm{RR}=1.65,95 \%$ CI 0.84 to 3.22 ). In general, for $\mathrm{SO}_{2}$, results showed an excess risk of more than $50 \%$ was unlikely, while the upper confidence limits for analyses of $\mathrm{NO}_{2}$ and $\mathrm{PM}_{10}$ frequently could not exclude a twofold risk (table 3).
Of the nine cardiac anomaly subtypes studied (27 associations), the association statistically least likely to be due to chance was between tetralogy of Fallot and $\mathrm{SO}_{2}$ (unadjusted $\mathrm{RR}=1.14$, fully adjusted $\mathrm{RR}=1.38,95 \% \mathrm{CI} 1.07$ to 1.79 ) (table 4), with similarly raised risks for $\mathrm{NO}_{2}$ (adjusted $\mathrm{RR}=1.44,95 \% \mathrm{CI}$ 0.71 to 2.93 ) and $\mathrm{PM}_{10}$ (adjusted $\mathrm{RR}=1.48,95 \% \mathrm{CI} 0.57$ to 3.84 ).

It was of note that in the unadjusted model, 10 non-chromosomal or cardiac anomaly subtypes showed statistically significant inverse associations with $\mathrm{PM}_{10}$ or $\mathrm{NO}_{2}$ or both (see online appendix), and there were two further positive statistically significant associations for $\mathrm{SO}_{2}$, showing the influence of model specification.

Results from models incorporating hospital catchment areas as fixed effects were very similar to the above random effects results (see online appendix). The positive associations between chromosomal anomalies and pollutants are reduced in size and significance, as is the association between omphalocele and $\mathrm{PM}_{10}$. The fixed effect model gives higher relative risks for tetralogy of Fallot in relation to all pollutants.

\section{DISCUSSION}

We could find no evidence of an association between average annual ambient $\mathrm{SO}_{2}, \mathrm{NO}_{2}$ or $\mathrm{PM}_{10}$ air pollution of area of residence and risk of non-chromosomal congenital anomaly as a whole. For chromosomal anomalies, the data were compatible with no or a small excess risk. For congenital anomaly subtypes, the power of the analysis was much lower, and non-significant raised risks with wide confidence intervals are difficult to interpret. We found two significant positive associations-between $\mathrm{SO}_{2}$ and tetralogy of Fallot (with raised relative risks also for $\mathrm{NO}_{2}$ and $\mathrm{PM}_{10}$ ), and between $\mathrm{PM}_{10}$ and omphalocele (with a raised risk also for $\mathrm{NO}_{2}$ ). Given the multiple comparisons involved in testing a large range of congenital anomaly subtypes against three pollution measures, these could easily be chance associations. However, the tetralogy of Fallot result could also be interpreted as supporting the sensitivity of this anomaly to air pollution; a study in Texas ${ }^{4}$ found a positive association between tetralogy of Fallot and carbon monoxide but not $\mathrm{SO}_{2}$, and a Californian study ${ }^{3}$ found a positive association between ozone exposure and conotruncal defects (a group which includes tetralogy of Fallot), but not carbon monoxide and did not analyse $\mathrm{SO}_{2}$. However, three further studies reported no association between tetralogy of Fallot or conotruncal defects and black smoke, ${ }^{5} \mathrm{PM}_{10},{ }^{67} \mathrm{SO}_{2},{ }^{5-7} \mathrm{CO},{ }^{67} \mathrm{NO}_{2}{ }^{67}$ and ozone. ${ }^{67}$

Consistent with the few previous studies, we found no evidence for association between any pollutant and oral cleft anomalies, ${ }^{3-6}$ or between $\mathrm{PM}_{10}$ and $\mathrm{NO}_{2}$ and cardiac anomalies as a whole. ${ }^{3}$ Our results do not support the association between $\mathrm{PM}_{10}$ and isolated atrial septal defects found in Texas. ${ }^{4} \mathrm{We}$ excluded isolated VSD from analysis since it can be variably reported, and thus have no further evidence relating to the association found with $\mathrm{SO}_{2}$ in Texas. ${ }^{4}$ We also did not analyse patent ductus arteriosus in term babies, found to be associated with $\mathrm{PM}_{10}$ in Atlanta. ${ }^{7}$ A level of discordance between study

Table 2 Summary relative risks for a change in pollution from the 10th to the 90th centile for non-chromosomal and chromosomal anomalies by pollutant

\begin{tabular}{|c|c|c|c|c|}
\hline \multirow[b]{2}{*}{ Pollutant } & \multicolumn{2}{|c|}{ Non-chromosomal anomalies $(n=6136)$} & \multicolumn{2}{|c|}{ Chromosomal anomalies $(n=2949)$} \\
\hline & $\begin{array}{l}\text { Unadjusted RR } \\
\text { (95\% Cl) }\end{array}$ & Adjusted RR (95\% Cl) & $\begin{array}{l}\text { Unadjusted RR } \\
\text { (95\% CI) }\end{array}$ & Adjusted RR (95\% Cl) \\
\hline $\mathrm{SO}_{2}$ & $1.02(0.98$ to 1.07$)$ & $0.99(0.93$ to 1.05$)$ & $0.98(0.91$ to 1.05$)$ & $1.06(0.98$ to 1.15$)$ \\
\hline $\mathrm{PM}_{10}$ & $0.74(0.69$ to 0.79$)$ & $0.89(0.75$ to 1.07$)$ & $1.05(0.96$ to 1.16$)$ & $1.18(0.97$ to 1.42$)$ \\
\hline
\end{tabular}


Table 3 Number of cases and adjusted relative risks $(95 \% \mathrm{CI})$ for an increase in pollution from the 10 th to the 90 th centile, by congenital anomaly subgroup, by pollutant

\begin{tabular}{|c|c|c|c|c|}
\hline & $\begin{array}{l}\text { No. of } \\
\text { cases }\end{array}$ & $\mathrm{SO}_{2}$ & $\mathrm{NO}_{2}$ & $\mathrm{PM}_{10}$ \\
\hline Neural tube defects & 1041 & $1.00(0.88$ to 1.14$)$ & $1.00(0.77$ to 1.31$)$ & $0.96(0.69$ to 1.34$)$ \\
\hline Hydrocephaly & 341 & 1.22 (0.98 to 1.52$)$ & 1.28 (0.73 to 2.23$)$ & $1.09(0.55$ to 2.18$)$ \\
\hline Cardiac defects & 1948 & $1.00(0.91$ to 1.10$)$ & $0.96(0.78$ to 1.19$)$ & $0.89(0.68$ to 1.17$)$ \\
\hline Cleft lip with or without cleft palate & 586 & $0.92(0.73$ to 1.15$)$ & $0.91(0.59$ to 1.40$)$ & $0.78(0.45$ to 1.35$)$ \\
\hline Cleft palate & 302 & $1.09(0.88$ to 1.35$)$ & $0.84(0.51$ to 1.38$)$ & $0.77(0.42$ to 1.40$)$ \\
\hline Digestive system atresias & 465 & $1.00(0.84$ to 1.20$)$ & 0.91 (0.62 to 1.35$)$ & $0.99(0.61$ to 1.58$)$ \\
\hline Bilateral renal agenesis & 92 & $0.92(0.60$ to 1.42$)$ & 1.09 (0.45 to 2.65$)$ & $0.85(0.29$ to 2.47$)$ \\
\hline Cystic kidney disease & 391 & $0.98(0.79$ to 1.22$)$ & $0.94(0.60$ to 1.46$)$ & $0.94(0.55$ to 1.62$)$ \\
\hline Limb reduction & 295 & $1.06(0.85$ to 1.32$)$ & $1.40(0.83$ to 2.36$)$ & $1.27(0.68$ to 2.38$)$ \\
\hline Diaphragmatic hernia & 203 & $1.07(0.83$ to 1.38$)$ & $1.06(0.60$ to 1.89$)$ & $1.30(0.63$ to 2.70$)$ \\
\hline Omphalocele & 183 & $1.08(0.80$ to 1.45$)$ & $1.65(0.84$ to 3.22$)$ & $2.17(1.00$ to 4.71$)$ \\
\hline Gastroschisis & 222 & $1.08(0.87$ to 1.33$)$ & 1.20 (0.69 to 2.11$)$ & $1.26(0.61$ to 2.58$)$ \\
\hline Multiple anomalies & 689 & 1.13 (0.99 to 1.29$)$ & $1.30(0.93$ to 1.83$)$ & $1.42(0.92$ to 2.21$)$ \\
\hline Down syndrome & 1486 & $1.08(0.96$ to 1.22$)$ & 1.07 (0.85 to 1.34$)$ & $1.09(0.82$ to 1.44$)$ \\
\hline
\end{tabular}

results must be expected due to the multiple comparisons made in each study.

Differences between countries may occur due to differences in the level and range of pollution experienced, and differences in unmeasured co-pollutants. We did not study $\mathrm{CO}$, ozone or polycyclic aromatic hydrocarbons. Mean levels of air pollution for all three air pollutants studied were comparable to or lower than those reported by two of the American studies of congenital anomalies. ${ }^{4}$ A study of air pollution in the Czech Republic reported a higher occurrence of heart defects related to organic solvents and phosphoric acid in particular, but there was no control for socioeconomic confounding. ${ }^{22}$ Most studies of air pollution and congenital anomalies have concentrated on specific point sources and their associated emissions such as vinyl chloride plants, smelters, solvent emitters, chemical plants and waste disposal sites. ${ }^{23} 24$

Our study has a number of strengths in relation to the very sparse existing literature. It examines a wide range of congenital anomalies. Cases include live births, late fetal deaths and terminations of pregnancy following prenatal diagnosis, the last of these being very important for some anomalies such as neural tube defects due to geographical variation in the proportion of terminations of pregnancy. The population size examined was bigger than in previous studies. ${ }^{3-7}$ Geocoding was virtually complete for cases as well as all births, thus eliminating incomplete geocoding as a potential source of bias.

One of the difficult problems of environmental epidemiology using congenital anomaly registries (as opposed to investigation of other fetal effects such as birth weight) is that such data are subject to geographical ascertainment variation, mainly related to the characteristics of the registries and their data sources, and to the hospitals and their diagnostic and reporting systems. No registry can claim to be totally free from this. All four included registries follow EUROCAT guidelines, and use active case ascertainment methods. ${ }^{12}$ In order to be sure that variation in prevalence was exposure related and not ascertainment related, we incorporated registry and hospital catchment area into our statistical model. Hospital catchment area adjustment is described in a previous paper using the same dataset, ${ }^{14}$ based on area of residence rather than hospital of delivery to avoid differences between hospitals relating to selective transfers of high risk pregnancies. This is the first time this methodology has been used in the geographical analysis of a specific type of pollution. Since a substantial component of the variation in pollution was between regions rather than subregional, the statistical power of our study was reduced. However, it is notable that the unadjusted results revealed more inverse associations than positive associations, and we suggest that inadequate geographical ascertainment adjustment may also explain the high number of inverse associations found in some other studies. ${ }^{4} 6$

Our study results should be interpreted in the light of several sources of misclassification of exposure, which may have diluted the estimated relative risks comparing geographical areas. The use of a single year's (1996) estimates to estimate the average for 1991-2000 would have introduced some classical error, although the high correlations for $\mathrm{PM}_{10}$ and $\mathrm{NO}_{2}$ between 1996 and 2001 estimates suggest that geographical patterns of these pollutants have not changed much over time, although for the markedly declining $\mathrm{SO}_{2}$ this would have been a bigger source of error. Even for 1996 the model estimates would be expected to have some

Table 4 Number of cases and adjusted relative risk $(95 \% \mathrm{Cl})$ for an increase in pollution from the 10th to the 90 th centile by congenital heart disease subgroup, by pollutant

\begin{tabular}{|c|c|c|c|c|}
\hline & $\begin{array}{l}\text { No. of } \\
\text { cases }\end{array}$ & $\mathrm{SO}_{2}$ & $\mathrm{NO}_{2}$ & $\mathrm{PM}_{10}$ \\
\hline Anomalies of cardiac chambers & 413 & $0.99(0.81$ to 1.20$)$ & $1.09(0.73$ to 1.64$)$ & $1.08(0.65$ to 1.80$)$ \\
\hline Transposition of great vessels & 251 & 0.94 (0.71 to 1.25$)$ & 1.15 (0.65 to 2.02$)$ & $1.22(0.59$ to 2.49$)$ \\
\hline Malformations of cardiac septa & 596 & $1.03(0.89$ to 1.19$)$ & 0.94 (0.68 to 1.30$)$ & 0.89 (0.59 to 1.37$)$ \\
\hline Atrioventricular septal defects & 109 & 0.98 (0.68 to 1.42 ) & $0.62(0.30$ to 1.30$)$ & $0.49(0.19$ to 1.27$)$ \\
\hline Tetralogy of Fallot & 146 & 1.38 (1.07 to 1.79$)$ & 1.44 (0.71 to 2.93$)$ & $1.48(0.57$ to 3.84$)$ \\
\hline Malformations of valves & 802 & $1.02(0.90$ to 1.16$)$ & 0.95 (0.71 to 1.26$)$ & $0.89(0.61$ to 1.30$)$ \\
\hline Hypoplastic left heart syndrome & 180 & 1.07 (0.80 to 1.44$)$ & 1.50 (0.77 to 2.89 ) & $1.22(0.56$ to 2.68$)$ \\
\hline Great arteries and veins & 580 & 0.98 (0.83 to 1.15$)$ & 0.96 (0.69 to 1.35$)$ & $0.82(0.53$ to 1.27$)$ \\
\hline Coarctation of aorta & 176 & 1.15 (0.90 to 1.47$)$ & 1.41 (0.76 to 2.62$)$ & $1.09(0.48$ to 2.46$)$ \\
\hline
\end{tabular}


error, as shown by the model validation results. While no air pollution estimate will be free from error, modelling such as that used here is designed to be an improvement over 'levels at nearest monitor' or similar approaches as used in other studies, ${ }^{3-7}$ where monitor levels are used for quite distant populations without the incorporation of further relevant information about local pollution sources. An additional source of exposure misclassification is movement and migration during pregnancy. Unpublished English data suggest that one quarter of women moved more than $2 \mathrm{~km}$ during pregnancy. Inevitably, studies based on residence at birth misclassify the exposure of some women who migrate. Moreover, even women who stay at the same residence do not stay within the $1 \mathrm{~km} \times 1 \mathrm{~km}$ grid squares to which they are allocated, but move more widely for work and recreation. This source of misclassification would be non-differential in the sense of being similar for cases and controls, and thus would dilute relative risk estimates, and in addition might lead us to overestimate exposure contrasts and thus underestimate risk.

We used a single estimate of average annual exposure rather than exposure in early pregnancy capturing seasonal exposure variation. To the extent that the modelled pollution values are well correlated across wards with the true annual averages, this would not lead to dilution of relative risk, as argued by Berkson, ${ }^{25} 26$ that is, our results are unbiased for the exposure contrast that we examined. Our choice of exposure model meant that we could not compare seasonal to spatial variation in exposure, although we note that our exposure contrasts (the difference between the highest and lowest levels of exposure) were similar to those in Texas averaged over only 6 weeks. On the other hand, the advantages of our approach are that we can be confident that any air pollution effects (positive or inverse) are not in fact due to uncontrolled seasonal variation ${ }^{5}$ due to other seasonally varying factors. Our results bear on the public health question of whether variation in exposure between wards leads to variation in congenital anomaly rate. If excess risk only occurs during rare short periods of very high exposure (considerably higher than our 90th centile), according to a threshold (rather than stochastic) model of teratogenesis, then such limited effects would not be seen in our results.

We adjusted for several important risk factors for anomalies, namely maternal age and area socioeconomic deprivation. Other risk factors such as smoking are highly correlated geographically with deprivation ${ }^{27}$ so their confounding impact would have been controlled to a considerable extent by adjusting for deprivation. While there is no strong expectation that other risk factors are strongly related both to congenital anomaly risk and to air pollution, other than through their association with deprivation, the possibility of confounding cannot be excluded, that is the lack of an overall air pollution effect was due to masking by a negative correlation between air pollution and other unmeasured risk factors.

In common with most ambient air pollution studies, we lacked data on indoor air pollution and its correlation with outdoor levels. The high correlation between $\mathrm{PM}_{10}$ and $\mathrm{NO}_{2}$ levels makes distinction of risks related to each uncertain, but as there are so few positive associations for these pollutants this has little practical consequence for interpretation.

This study found evidence that geographical variation in average exposure to the air pollutants $\mathrm{NO}_{2}, \mathrm{SO}_{2}$ and $\mathrm{PM}_{10}$ in the 1990s did not lead to sustained geographical differences in overall congenital anomaly rate in England. This does not imply that air pollution does not raise the risk of specific congenital anomalies, and our results indicate the need for further research regarding specific anomalies, especially tetralogy of Fallot. Our results are not necessarily generalisable to other populations where the pollution contrasts are greater or the mixture different.

Funding The study was supported by the Department of Health (London) Policy Research Programme. The views expressed are not necessarily those of the Department of Health. JR is funded by a Personal Award Scheme Career Scientist Award from the National Institute of Health Research.

\section{Competing interests None.}

Ethics approval This study was conducted with the approval of the London School of Hygiene \& Tropical Medicine Ethics Committee.

Provenance and peer review Not commissioned; externally peer reviewed.

\section{REFERENCES}

1. Sram RJ, Binkova B, Dejmek J, et al. Ambient air pollution and pregnancy outcomes: a review of the literature. Environ Health Perspect 2005;113:375-82.

2. Glinianaia SV, Rankin J, Bell R, et al. Particulate air pollution and fetal health: a systematic review of the epidemiologic evidence. Epidemiology 2004:15:36-45.

3. Ritz B, Yu F, Fruin S, et al. Ambient air pollution and risk of birth defects in Southern California. Am J Epidemiol 155:17-24.

4. Gilboa SM, Mendola P, Olshan AF, et al. Relation between ambient air quality and selected birth defects, seven county study, Texas 1997-2000. Am J Epidemiol 2005:162:238-52.

5. Rankin J, Chadwick T, Natarajan M, et al. Maternal exposure to ambient air pollutants and risk of congenital anomalies. Environ Res 2009;109:181-7.

6. Hansen CA, Barnett AG, Jalaludin BB, et al. Ambient air pollution and birth defects in Brisbane, Australia. PloS One 2009:4:e5408. doi:10.1371/journal.pone.005408.

7. Strickland MJ, Klein M, Correa A, et al. Ambient air pollution and cardiovascular malformations in Atlanta Georgia 1986-2003. Am J Epidemiol 2009;169:1004-14.

8. Little J. Smoking. In: EUROCAT Special Report. A Review of Environmental Risk Factors for Congenital Anomalies. 2004, 83-8. http://www.eurocat-network.eu/ content/Special-Report-Env-Risk-I-and-II.pdf.

9. Honein MA, Rasmussen SA, Reefhuis J, et al. Maternal smoking and environmental tobacco smoke exposure and the risk of orofacial clefts. Epidemiology 2007:18:226-33.

10. Torfs CP, Christianson RE, lovannisci DM, et al. Selected gene polymorphisms and their interaction with maternal smoking, as risk factors for gastroschisis. Birth Defects Res A Clin Mol Teratol 2006;76:723-30.

11. Kallen K. Maternal smoking during pregnancy and limb reduction malformations in Sweden. Am J Public Health 1997;87:29-32.

12. Rankin J, Pattenden S, Abramsky L, et al. Prevalence of congenital anomalies in five British regions, 1991-99. Arch Dis Child Fetal Neonatal Ed 2005;90:F374-9.

13. Dolk H, Abramsky L, Armstrong B, et al. A study of the geographical variation in overall rates of congenital abnormalities and the rates of specific abnormalities. Report to the Department of Health, 2003. http://www.eurocat-network.eu/content/SpecialReport-Geo-Het.pdf.

14. Armstrong B, Dolk H, Pattenden S, et al. Geographic variation and localized clustering of congenital anomalies in Britain. Emerging Themes Epidemiol 2007;4:14. PMID: 17617898.

15. <http://www.eurocat-network.eu/ABOUTUS/MemberRegistries/ MembersAndRegistryDescriptions/FullMembers.

16. Carstairs V, Morris R. Deprivation and health in Scotland. Health Bull (Edinb) 1991:48:162-75

17. EUROCAT Guide 1.2. Instructions for the Registration of Congenital Anomalies University of Ulster, 2002. http://www.eurocat-network.eu/ABOUTUS/DataCollection/ GuidelinesforRegistration/PreviousCodingGuides/InstructionManuals.

18. Wellesley D, Boyd P, Dolk H, et al. An aetiological classification of birth defects for epidemiological research. J Med Genet 2005:42:54-7.

19. Stedman JR. Revised high resolution maps of background air pollutant concentrations in the UK: 1996. Report Number AEAT-3133 20008001/006 Issue 2. March 1998.

20. Stedman JR, Bush TJ, Vincent KJ. UK air quality modelling for annual reporting 2001 on ambient air quality assessment under Council Directives 6/62/EC and 1999/30/EC. Report to The Department for Environment, Food and Rural Affairs, Welsh Assembly Government, The Scottish Executive and the Department of the Environment for Northern Ireland. 2002

21. Lindsey JK. A review of some extensions to generalized linear models. Stat Med 1999;18:2223-36.

22. Smrcka V, Leznarova D. Environmental pollution and the occurrence of congenital defects in a 15 year period in a south Moravian district. Acta Chir Plast 1998:40:112-4.

23. KuehI KS, Loffredo CA. A cluster of hypoplastic left heart malformation in Baltimore Maryland. Pediatr Cardiol 2006;27:25-31.

24. Vrijheid M, Loane M, Dolk H. Chemical environmental and occupational exposures. In: EUROCAT Special Report. A review of environmental risk factors for congenital anomalies. University of Ulster, 2004. http://www.eurocat-network.eu/content/ Special-Report-Env-Risk-III.pdf.

25. Armstrong BG. Effect of measurement error on epidemiological studies of environmental and occupational exposures. Occup Environ Med 1998;55:651-6.

26. Zeger SL, Thomas D, Dominici F, et al. Exposure measurement error in time-series studies of air pollution: concepts and consequences. Environ Health Perspect 2000:108:419-26.

27. Kleinschmidt I, Hills M, Elliott P. Smoking behaviour can be predicted by neighbourhood deprivation scores. J Epidemiol Community Health 1995:49(Suppl 2):S72-7. 